\title{
Корпоративное управление и корпоративные результаты: эмпирические доказательства на опыте стран с растущим рынком капитала
}

\author{
Степанова A.H. ${ }^{33}$
}

\begin{abstract}
В этой статье мы предлагаем вамему вниманию обзор представленных на конференции эмпирических работ, изучающих проблему взаимосвязи корпоративного управления и результатов деятельности компаний в России. Во-первых, мы сравнили различные взгляды теоретиков и практиков на состав и роль совета директоров в условиях растущих рынков капитала, сопоставляя выводы профессора Андрея Верникова (ГУ-ВШЭ, экс-председатель совета директоров МДМ-Банка) с эмпирическими результатами исследования Иииро Ивасаки (Hitotsubashi University) и некоторыми выводами Ирины Ивашковской и Анастасии Степановой (ГУ-ВШЭ). Во-вторых, мы рассмотрели подходы и результаты исследований влияния структуры собственности и качества корпоративной эффективности на эффективность деятельности компании, предложенные в работе Ирины Ивашковской, Артема Рашупкина и Ярослава Осипова (ГУ-ВШЭ) и Игоря Беликова (Российский институт директоров) и в докладе Иринь Ивашковской и Анастасии Степановой. Наибольший интерес, на наш взгляд, представляет попытка сопоставить выводы эмпирических исследований, изучающих разные компоненты корпоративного управления, чтобы получить полную картину того, как развивается система КУ в российских компаниях.
\end{abstract}

\section{Введение}

Одной из актуальных тем конференции стала проблема взаимосвязи деятельности советов директоров и результатов деятельности компаний в России. Данная проблематика остается в числе нерешенных академических вопросов применительно к опыту корпоративного управления в странах с развитой рыночной экономикой и, безусловно, далека от решения применительно к российскому бизнесу. Этим вопросам на конференции были посвящены совместный доклад Ирины Ивашковской, Артема Ращупкина и Ярослава Осипова из лаборатории корпоративных финансов ГУ-ВШЭ и Игоря Беликова (Российский институт директоров), доклады Иширо Ивасаки из Института экономических исследований Hitotsubashi University, Андрея Верникова из ГУ-ВШЭ.

Немало внимания докладчики уделили проблемам, связанным с составом и функциями совета директоров. В докладе профессора ГУ-ВШЭ Андрея Верникова на тему «Роль советов директоров в системе корпоративного управления, создаваемой контролирующими акционерами» подняты наиболее актуальные проблемы, связанные с деятельностью совета директоров в современной России. В докладе Иширо Ивасаки на тему «Эндогенность состава совета директоров и детерминирующие его факторы в переходной экономике на примере российских компаний» представлены результаты исследования, проведенного на данных российских компаний, в ходе которого он попытался продемонстрировать эндогенный характер состава совета директоров и выделить основные факторы, которые в норме определяют состав коллегиального органа в российских компаниях. Эти два доклада, хотя затрагивают одну и ту же проблему, подготовлены совершенно в разных стилях: если Ивасаки пытается использовать как можно больше переменных с целью выявить

\footnotetext{
33 Преподаватель кафедры экономики и финансов фирмы ГУ-ВШЭ, сотрудник Научно-исследовательской Лаборатории корпоративных финансов при факультете экономики ГУ-ВШЭ
} 
детерминанты состава совета директоров, то подход Верникова, напротив, заключается в поиске единственной наилучшей прокси-переменной для количественного измерения вовлеченности тех или иных стейкхолдеров в процесс корпоративного управления. В совместном докладе профессора ГУ-ВШЭ, руководителя Лаборатории корпоративных финансов Ирины Ивашковской, Артема Ращупкина, Ярослава Осипова, Игоря Беликова, подготовленном в рамках проекта Лаборатории совместно с Российским институтом директоров (РИД) и КПМГ, поставлена задача выявить характер зависимости между качеством корпоративного управления и корпоративной эффективностью. Тема доклада сформулирована так: «Советы директоров и корпоративная эффективность в переходной экономике: исследование на базе Национального рейтинга РИД-Эксперт РА». Но предложенный в этом совместном докладе метод - не единственный способ моделировать влияние корпоративного управления на эффективность деятельности компании. Еще один взгляд на изучаемую зависимость представлен в докладе Ирины Ивашковской и Анастасии Степановой (лаборатория корпоративных финансов ГУ-ВШЭ) «Влияние структуры собственности на корпоративную эффективность в условиях растущего рынка капитала». Авторы предлагают рассмотреть влияние структуры собственности как одного из интегрированных компонентов корпоративного управления на эффективность деятельности компании на примере российских и европейских компаний.

В настоящем обзоре обобщены дискуссионные вопросы, поднятые в этих докладах. В первой части мы предложим вашему вниманию различные взгляды на состав и роль совета директоров в условиях растущих рынков капитала, сопоставляя выводы Андрея Верникова с эмпирическими результатами исследования Иширо Ивасаки и некоторыми выводами Ирины Ивашковской и Анастасии Степановой. Во второй части будут рассмотрены подходы и результаты исследований влияния корпоративной эффективности на эффективность деятельности компании.

\section{1. Состав и роль совета директоров в условиях российской экономики}

\section{1. Агентские конфликты и совет директоров}

Доклад профессора Высшей школы экономики Андрея Верникова отражает взгляды практикующего члена совета директоров в России. Очевидно, что выводы опираются на личный опыт работы независимым директором в российских компаниях, преимущественно в банковском секторе. Автор сознательно жертвует нормативно-дидактическим подходом, отдавая предпочтение реальным интересам участвующих сторон, их отношениям и конфликтам.

Краеугольным камнем теории и практики корпоративного управления, центральным элементом которой является представительный, независимый и сильный совет директоров, являются «агентские конфликты»: распыленная структура акционерного капитала, отделение собственности от управления, появление в компании портфельных инвесторов - все это создает питательную среду для оппортунистического поведения как менеджеров, так и акционеров. Ряд исследований, проведенных на данных растущих капитала, показал, что действие теории корпоративного управления отнюдь не столь универсально. Нельзя не согласиться с утверждением автора, что за пределами англо-саксонских стран распыленная форма собственности встречается достаточно редко, а в большинстве стран мира преобладают компании, в которых есть контролирующие акционеры, или блокхолдеры.

Андрей Верников утверждает, что к числу стран с высококонцентрированной собственностью относится и Россия. В условиях России распыленная структура акционерного капитала и отсутствие «хозяина» воспринимаются как аномальное неустойчивое состояние, опасное для выживания банка. По словам автора, в списке тридцати крупнейших коммерческих банков России не удалось обнаружить ни одного банка с признаками распыленной структуры собственности. Многие из ведущих частных банков 
фактически имеют одного хозяина. Безусловно, автор относит этот момент к негативным сторонам корпоративного управления в России. Однако нельзя не вспомнить, что структура собственности в России гораздо более диверсифицированная, чем, например, в Турции, где любая относительно рентабельная компания входит в один из крупнейших холдингов страны, каждый из которых, как правило, на 100\% принадлежит одной семье. Можно насчитать несколько кланов, которые устанавливают правила игры во всей стране.

Вернемся к ситуации в России. Автор отмечает, что, несмотря на рост числа независимых директоров, качественно ситуация с низким уровнем развития корпоративного правления не изменилась. Сегодня приглашения независимых директоров - это элемент предпродажной подготовки банка и вынужденная уступка внешним механизмам принуждения участников рынка к соблюдению определенного набора правил поведения. В общем, можно отметить, что в этом случае автор выражает мнение большинства топменеджеров российских компаний. Как показали результаты проведенного МФК исследования корпоративного управления в банках России, за последние три года собственники не начали более активно играть роль финансовых инвесторов, делегирующих бизнес-решения профессиональному совету директоров либо правлению. Исследование позволило показать, что собственники предпочитают осуществлять прямой контроль за деятельностью банка: в 53\% случаев главный акционер банка является членом совета директоров, еще у $39 \%$ банков в совет директоров входит второй по значению собственник банка, в 36\% банков - третий по значению акционер [МФК 2007]. ${ }^{34}$ По мнению автора, истинные показатели еще выше, поскольку российские правила раскрытия информации оставляют собственникам возможность скрывать свою идентичность за номинальными держателями акций банка.

Как следствие всего вышеупомянутого, автор делает вывод, что роль совета директоров как органа, представляющего и гармонизирующего интересы большого числа находящихся где-то далеко акционеров, в России объективно востребована лишь частично. Это вывод, с которым согласится не каждый, но который, конечно, заставляет задуматься об уровне качественного развития системы корпоративного управления. Безусловно, в российской действительности наиболее распространен случай, когда акционеров в каждом из банков совсем немного. И конечно, они предпочитают лично входить в состав руководящих органов банка и возглавлять эти органы. Вопрос лишь в том, так ли уж это плохо и нужно ли это менять. Андрей Верников в качестве формулировки основной проблемы утверждает, что в этих специфических условиях совет директоров призван решать «агентскую проблему» в основном в государственном секторе, где собственность фактически бесхозная, а также в тех редких частных банках, владельцы которых действительно решили «отойти от дел».

Интересно, что один из выводов, представленных в ходе конференции Ириной Ивашковской и Анастасией Степановой, утверждает, что в России концентрация собственности в руках акционеров, которые непосредственно вовлечены в процесс корпоративного управления, положительно влияет на эффективность деятельности компаний. Этот вывод не противоречит утверждению о высокой концентрации собственности в российских банках, но не позволяет авторам согласиться с тем, что совет директоров в России не решает «агентской проблемы». Между тем, безусловно, нельзя отрицать, что права миноритариев во многих российских компаниях ущемляются, и российская законодательная система неидеальна в области защиты прав акционеров.

\subsection{Governance vs. Management}

Многие ученые отмечают неразвитость общественных институтов, обеспечивающих эффективную защиту прав собственности [Авдашева С.Б., 2004; Капелюшников Р.И., 2005;

\footnotetext{
${ }^{34}$ Данные взяты из проведенного МФК исследования корпоративного управления в российских банках [МФК 2007].
} 
Радыгин А.Д. и Энтов Р.М., 2001], что вынуждает российских собственников непосредственно участвовать в управлении принадлежащими им банками. Автор утверждает, что неразделенность функций собственности и управления, хотя и вызывается объективными причинами, бросает вызов классической теории корпоративного управления. Интересно, что думали по этому поводу такие ученые классической школы, как Ллойд и Шляйфер ]Lloyd или Shleifer]/ C начала 80-х гг. XX в. много внимания уделяется эмпирическому выявлению зависимости между количеством акций в руках инсайдеров и корпоративной эффективностью. После выхода в свет широко известной работы Морка, Шляйфера и Вишны [Morck, Shleifer и Vishny, 1988] мнения ученых насчет влияния собственности инсайдеров на эффективность деятельности компании разделились. Ряд исследований структуры собственности компаний привел их авторов к выводу об отсутствии сколько-нибудь значимого влияния ее на стоимость компании или другие показатели эффективности деятельности. Среди этих работ - исследование Ллойда, Джахеры и Голдштайна [Lloyd, Jahera, Goldstein,1986] и работа Идален Кеснер [Idalene Kesner, 1987]. Другие утверждают, что инсайдерская собственность положительно влияет на эффективность деятельности компании. Родоначальником этой теории стал Ванс [Vance, $1955,1964]$, а из более поздних работ целесообразно выделить статьи Кима, Ли, Френсиса [Kim, Lee, Francis 1988] и Шелленгера, Вуда, Ташакори [Schellenger, Wood, Tashakori, 1989]. Третий тип исследований выявил немонотонное, U-образное влияние: оно положительно для небольших пакетов акций в руках менеджеров и отрицательно для больших пакетов. Первыми немонотонную зависимость выявили Морк, Шляйфер и Вишны [Morck, Shleifer и Vishny] в 1988 г.

Данный обзор результатов исследований мировых ученых был использован в работе Ирины Ивашковской и Анастасии Степановой с целью выбора переменных для моделирования корпоративной эффективности. Суммируя выводы этих двух исследований, можно сказать, что, несмотря на то что относительная неразделенность функций собственности и управления бросает вызов классической теории корпоративного управления, она в то же время позволяет достигать высокой эффективности деятельности компании.

В работе Андрея Верникова предложен интересный взгляд на проблему неразделенности собственности и управления. Теоретически управление в компании всегда разделено на управление стратегическими решениями (совет директоров) и управление оперативной деятельностью (менеджмент, правление). На взгляд автора, российский менталитет не различает понятия management и governance - не случайно в русском языке они передаются одним и тем же термином «управление». По его наблюдениям, governance в отрыве от management в российском банке пока не получил большого развития, и сложно сказать, может ли он существовать в принципе. В 13\% российских банков главный акционер является членом правления. Это, разумеется, не означает, что в остальных $87 \%$ банков ключевой акционер устраняется от принятия управленческих решений и занимается исключительно стратегией. Действительно, обладая в компании высокими полномочиями в силу своего права собственности, крупный акционер обычно плохо представляет себе различие между governance и management и не готов применять это различие на практике, особенно если предшествующий жизненный опыт был в основном управленческим. Отказаться от активной руководящей роли бывает трудно, да и возникает классический вопрос: «Кто сделает лучше, чем я?» По мнению профессора Верникова, часто тенденция к узурпации управленческих решений ничем не сдерживается и не находит и противовесов ввиду слабости институтов корпоративного управления и преобладания неформальных норм поведения над формальными. Ученых, работающих с процессами корпоративного управления, всегда поджидают проблемы с оцифровыванием показателей. Все категории, с которыми они работают, качественного характера. Сложно оценить реальную степень участия акционера в управлении банком в количественных терминах. Анкетирование сотрудников банка часто отражает лишь формальную сторону и поэтому искажает 
статистический результат. Для преодоления неполноты информации автор предлагает собственный простой и наглядный критерий: наличие $y$ крупного акционера (или бенефициара) рабочего кабинета в здании банка. Очевидно, что для реализации функции собственника постоянный офис не нужен; если же он есть, то это означает непосредственное участие данного акционера в менеджменте. Не важно, является ли он членом совета директоров или нет: все равно все члены совета не могут постоянно присутствовать в банке и участвовать во все тех же встречах и совещаниях, которые проводит акционер.

Как уже было отмечено, в ходе конференции представлены два мнения на участие крупного акционера в управлении. Согласно докладу Андрея Верникова, участие крупного акционера в управлении генерирует серьезный конфликт интересов. Согласно выводам Ирины Ивашковской и Анастасии Степановой, участие крупного акционера в процессе управления позволяет сонаправить интересы менеджмента компании и ее акционеров и тем самым снизить агентские издержки. Каждый из этих взглядов самобытен и вызывает споры среди ученых. Если выводы Ивашковской И. и Степановой А. опираются на результаты классических эмпирических исследований и своего собственного исследования, то мнение Верникова А. подтверждается его многолетними наблюдениями и высоким уровнем профессионального опыта в практической среде. Следует также отметить, что работа Верникова направлена исключительно на изучение российских банков, тогда как в статье Ивашковской и Степановой исследование проводится на базе нефинансовых компаний.

\section{3. Совет директоров и независимый директор}

Еще один интересный аспект, затронутый Андреем Верниковым в ходе его выступления, - это роль совета директоров и роль независимого директора, если таковой все же вошел в состав совета директоров. Более половины опрошенных банков заявляют о наличии независимых членов в составе советов директоров, при всей условности российского понимания «независимости». Мы уже говорили, что в реальности независимые директора обычно появляются в банке в преддверии выхода на рынки капитала, с тем чтобы выполнить формальные требования, предъявляемые фондовыми биржами и внешними инвесторами. Но какой бы ни была причина, появление в российских банках внешних директоров вызвало всплеск до сих пор не утихающего энтузиазма, возродило надежды на лучшее будущее российского корпоративного управления и стало главным свидетельством улучшения его «качества».

Но чего на практике ожидает российский акционер от независимого директора? Наряду с вкладом в повышение инвестиционной привлекательности банка собственники ожидают от внешних директоров помощи в разработке бизнес-стратегии, развитии отношений с потенциальными инвесторами и внешним миром в целом, привлечении новых крупных клиентов и источников финансирования, лоббировании интересов банка в органах власти. Однако что происходит, если независимого директора привлекают исключительно исходя из формальных требований?

Результаты исследования, проведенного профессором Верниковым, показывают, что:

- лишь в одном из трех частных банков от совета директоров ожидают контроля и надзора за деятельностью исполнительного руководства;

- специализированные комитеты не действовали в 63\% опрошенных банков;

- комитет по аудиту есть лишь у $17 \%$ банков;

- менее чем в половине случаев комитет совета директоров по аудиту возглавляет независимый директор;

- в большинстве российских банков отвергается идея о том, что совет директоров должен заниматься подбором, назначением и увольнением СЕО и определением условий его контракта. 
Андрей Верников здесь вводит понятие «декоративности» совета директоров. По мнению автора, о декоративности совета директоров и института независимых директоров может свидетельствовать ряд объективных признаков:

- отсутствие у совета рабочих органов (комитетов);

-приглашение в совет иностранных специалистов, не владеющих русским языком и проживающих в другой стране;

-большое количество заочных голосований и малое количество очных заседаний совета;

- краткость заседаний;

-единогласное голосование по всем вопросам повестки в течение года.

Правомерный вопрос: если результат голосования директора на 100\% предопределен голосованием блокхолдера, может ли такое лицо считаться независимым директором? Независимость директоров является не только и не столько финансовой проблемой, как полагают многие специалисты, сколько социокультурной. Для компаний англосаксонского мира несовпадение интересов отдельных акционеров и групп акционеров, конкуренция и борьба между ними, в том числе в формате совета директоров, совершенно нормальны. В России же любое отклонение от консенсуса воспринимается как кризис в управлении.

Многолетний практический опыт позволяет профессору Верникову сделать следующий вывод: как правило, под формой директорства скрывается иное содержание, а именно работа в качестве более или менее независимого советника при ключевом акционере. Совет директоров работает по существу в режиме консультативного совета. Автор выделил также более редкий случай, когда степень вовлеченности директора настолько велика, что грань между независимым директорством и менеджментом стирается. Для анализа содержательных аспектов корпоративного управления профессор снова предлагает использовать «кабинетный тест». Если директору выделен в банке служебный кабинет и хотя бы минимальный аппарат, то это значит, что данное лицо фактически влилось в корпус топ-менеджмента. Таким образом, очевиден вывод, что номинальный статус независимого директора может расходиться с истинными функциями и ролью такого лица. При высокой концентрации собственности и личном участии блокхолдера в управлении «независимое директорство» видится как неустойчивая институциональная форма, подверженная переходу в иное качество - на роль советника либо менеджера.

Необходимо остановиться на еще одном аспекте, затронутом на конференции: выбор модели или структуры корпоративного управления, а также распределение функций внутри системы.

В докладе Верникова демонстрируется целесообразность использования двух коллегиальных органов управления в России. По мнению автора, в частном банке, где есть контролирующий акционер, содержание корпоративного управления сводится к защите интересов миноритариев от его оппортунистического поведения, а также к ограждению высших исполнительных органов банка от его прямого вмешательства в руководство. И если борьба за права миноритариев - дело совета директоров, то решение второй проблемы может состоять в повышении роли правления банка за счет полномочий СЕО и совета директоров. С другой стороны, сам автор указывает, что параллельное функционирование в компании двух авторитетных органов, претендующих на принятие важных управленческих решений, «приводит к двоевластию, дезориентации и демотивации менеджеров высшего и среднего звена, хаосу в управлении - и, как следствие, к разрушению стоимости». Таким образом, прикладывая вывод автора к данному утверждению, мы получим, что идеальный вариант строгое разграничение функций стратегических и оперативных и их отнесение к функциям совета директоров и правления соответственно.

Нельзя, однако же, забывать, что вывод не бесспорен и существует устойчивое мнение, говорящее о необходимости участия акционеров в управлении компанией, поскольку интерес менеджеров, как правило, заключается не в росте стоимости компании, а росте их личного дохода (бонуса, заработной платы и неденежных преимуществ).

\section{Выпуск \#4, 2007 \\ () Электронный журнал Корпоративные Финансы, 2007}




\section{4. Факторы, определяющие состав совета директоров}

На сегодняшний день существует ряд сложно разрешимых проблем, связанных с деятельностью совета директоров в России. Однако остается открытым вопрос, что влияет на формирование того или иного совета директоров. Почему в совете мало независимых директоров, что определяет его размера? Данные аспекты стали предметом исследования, представленного Иширо Ивасаки и проведенного им на данных российских компаний, в ходе которого он попытался ответить на эти непростые вопросы.

На выборке из 822 промышленных и телекоммуникационных компаний Ивасаки наглядно продемонстрировал эндогенный характер совета директоров. База данных, собранная совместно Высшей школой экономики и Hitotsubashi University, позволила выявить интересные результаты.

Во-первых, получилось, что в большинстве компаний в совет директоров входит 5 или 7 человек. Во-вторых, в среднем на 44\% совет директоров состоит из топ-менеджеров компаний, еще 5\% составляют работники и профсоюзы. Остальные 51\% - это внешние директора, среди которых более $75 \%$ - представители акционеров, не являющихся инсайдерами компании. Независимые директора составляют в среднем всего 6,5\% совета директоров. Если перевести эту цифру в абсолютные показатели, то мы получим, что далеко не в каждом совете директоров есть хотя бы один независимый директор. Для сравнения можно сказать, что представители государственных структур встречаются в совете директоров так же часто, как независимые директора. Ивасаки получил еще один оригинальный результат. При изучении частоты распределения внешних директоров внутри совета получилось, что модальное значение находится в пределах $10 \%$ внешних директоров от всего состава совета. Вторыми по популярности являются советы, полностью состоящие из внешних директоров или включающие 1 инсайдера (такие компании составили 30\% от выборки). Значительно реже встречаются компании, в которых поровну инсайдеров и внешних директоров.

Теперь обратимся к выводам относительно председателей совета директоров: в 46\% случаев это инсайдер. В том случае, если председателем является внешний директор, то с приблизительно равной вероятностью (40\%) это окажется человек, вращающийся в сфере деятельности компании, и тот, кто работает в другом секторе экономики. Основная гипотеза, сформулированная господином Ивасаки, заключается в эндогенном характере состава совета директоров, а именно в существовании взаимозависимостей между размером совета директоров, процентом внешних директоров и присутствием внешнего директора в качестве председателя совета. Модель, предложенная автором, включила в себя большое число факторов, которые были разбиты на три группы. В первую вошли переменные, связанные непосредственно со структурой собственности, такие как процент акций в руках менеджеров, директоров и крупных акционеров, собственность СЕО и наличие аффилированности с какой-либо крупной промышленной группой. В группу переменных, связанных с другими аспектами корпоративного управления, Ивасаки отнес юридическую форму компании, ее размер, возраст ухода на пенсию СЕО, ограничения на пакет акций и право голоса и другие. В третью группу были включены переменные, связанные с характером бизнеса компании, такие как диверсификация деятельности, структура капитала, затраты на R\&D, уровень конкуренции в отрасли и т.д.

Основные выводы, полученные Иширо Ивасаки в ходе исследования, заключаются в следующем:

- Топ-менеджеры и инвесторы в современной России организуют систему мониторинга, используя опыт зрелых капиталистических рынков.

- Процесс формирования совета директоров соответствует гипотезе переговорной силы, предложенной Hermalin и Weisbach [1998], которая предполагает, что совет 
директоров определяется в результате процесса переговоров между СЕО и директорами, что может свидетельствовать о незрелости социально-экономической системы страны.

- Особенности российской законодательной системы оказывают сильное влияние на процесс определения состава совета директоров. Политическое прошлое многих бизнесменов влияет на процесс принятия решений в российских компаниях.

- Что касается эндогенности переменных, то эмпирика подтверждает лишь зависимость между процентом внешних директоров и шансом, что председателем окажется внешний директор, что, на наш взгляд, соответствует законам теории вероятности.

Отметим в заключение, что наиболее значимыми в модели оказались переменные, включенные в первую группу, то есть индикаторы структуры собственности. Здесь можно провести прямую аналогию с исследованием влияния структуры собственности на корпоративную эффективность, проведенным Ириной Ивашковской и Анастасией Степановой. Иширо Ивасаки показал, что структура собственности во многом определяет структуру совета директоров в России. Совет директоров, в свою очередь, принимает стратегические решения, влияющие на эффективность деятельности компании. Но об этом пойдет речь во второй главе обзора.

\section{2. Влияние различных аспектов корпоративного управления на эффективность деятельности компаний}

\section{1. Влияние качества корпоративного управления на эффективность ее деятельности}

Очевидно, что практиков мировых финансов корпоративное управление интересует не просто так. Они заинтересованы в его качестве, поскольку оно определяет стоимость компании, цену акций, рентабельность и другие показатели корпоративной эффективности. Если первые две работы, предложенные вашему вниманию в настоящем обзоре, касаются внутренних аспектов корпоративного управления (а именно совета директоров, отвечающего за претворение в жизнь стратегии КУ), то следующие два исследования, о которых пойдет речь, делают еще один шаг, изучая влияние корпоративного управления на те или иные показатели эффективность деятельности компании.

Проблема взаимосвязи качества корпоративного управления и результатов деятельности компании продолжает оставаться в центре внимания мира ученыхфинансистов. Сегодня не прекращаются споры относительно роли корпоративного управления и критериев оценки результативности компании, а значит, и понимание механизма такой возможной взаимосвязи неоднозначно. В исследовании, проведенном в лаборатории корпоративных финансов на основе рейтинга РИД-Экперт РА, для анализа таких взаимозависимостей предлагается подход, сфокусированный на стратегически ориентированной роли и функциях советов директоров. Авторы ставят задачу эмпирического исследования деятельности совета директоров в российских компаниях на основе критерия создания экономической прибыли.

Российская практика корпоративного управления с позиций ее влияния на рыночную капитализацию компаний уже стала предметом ряда исследований. Авторы доклада ссылаются на известную работу Блэка [Black, 2001], подтверждающую наличие значимой корреляции между рейтингами корпоративного управления Standard\&Poor's и уровнем рыночной капитализации компаний [7]. Блэк пришел к выводу о возможности значительного увеличения капитализации компании в России - до $700 \%$ - при росте рейтинга корпоративного управления от худшего к наиболее высокому. Тот же результат был получен в ходе повторного исследования в 2007 г., но потенциал роста снизился до 87\%. Эти работы являются хорошей базой для дальнейших эмпирических исследования корпоративного управления и эффективности российских компаний.

Ирина Ивашковская, Артем Ращупкин, Ярослав Осипов и Игорь Беликов продолжают традицию комплексного подхода к характеристике качества корпоративного управления. 
Они формулируют смысл корпоративного управления в целом как «обеспечение стратегической эффективности компании»; другими словами, цель корпоративного управления - выстроить «стратегически ориентированную систему корпоративного управления». Авторы рассматривают проблему результативности компании «через призму исполнения корпоративной стратегии», то есть деятельность совета директоров должна способствовать повышению эффективности стратегических решений. Таким образом, ключевая гипотеза заключается в следующем: в компаниях со стратегически ориентированными советами директоров существует прямая положительная связь качества корпоративного управления и эффективности исполнения стратегии российских компаний, измеряемой через экономическую прибыль.

Основным техническим вопросом в подобном исследовании является выбор переменных для ключевых показателей модели: качества корпоративного управления и эффективности деятельности. По мнению авторов, применение бухгалтерских показателей в данном случае нецелесообразно, поскольку они не отражают инвестиционных рисков бизнеса, без чего оценивать результативность исполнения корпоративных стратегии в условиях рыночной конкуренции некорректно. Базируясь на финансовой, а не бухгалтерской концепции анализа деятельности компании, в качестве показателя эффективности они выбирают одну из моделей семейства экономической прибыли (residual income), а именно экономическую добавленную стоимость (есоnomic value added, EVA). Необходимо отметить, что именно эта модель вызывает сегодня наиболее пристальный интерес у российских компаний, стремящихся перейти к эффективным способам мониторинга вклада различных подразделений компании в прирост ее стоимости. Кроме того, существует дополнительное преимущество ее использования по сравнению с рыночными показателями, например коэффициентом Q Тобина. Многие исследование показали, что анализ взаимосвязи между показателями качества корпоративного управления и рыночной капитализацией компании не свободен от эндогенности, что снижает качество модели. Кроме того, использование нерыночного показателя позволит в дальнейшем включить в анализ компании, не котирующиеся на биржах.

Для расчета EVA была использована упрощенная формула:

$\mathrm{EVA}=(\mathrm{ROCE}-\mathrm{WACC}) \times \mathrm{CE}$,

где:

ROCE - return on capital employed - доходность инвестированного капитала;

CE - capital employed - инвестированный капитал;

WACC - weighted average cost of capital - средневзвешенные затраты на капитал.

Для анализа использовались данные по 41 российской компании, у которой есть отчетность по международным стандартам либо GAAP USA и значения Национального рейтинга корпоративного управления Российского института директоров - Эксперт (РИДЭксперт) за 2004, 2005 и 2006 гг.. Таким образом, всего в выборке 123 наблюдения. В качестве контрольных переменных были выбраны размер компании, ее операционный риск, показатель структуры капитала, уровень капитальных инвестиций относительно совокупных активов, фиктивная переменная государственного контроля и для 7 секторов экономики.

Однако, в противоречие гипотезе, в ходе исследования была выявлена отрицательная зависимость между качеством корпоративного управления и стратегической эффективностью компаний. По мнению авторов, это можно рассматривать как индикатор состояния деятельности советов директоров в российских компаниях. Судя по всему, совет директоров средней компании пока не фокусирует свои действия именно на задаче обеспечения стратегической эффективности, а работает над выстраиванием системы корпоративного управления. Однако авторы уверены: после завершения полосы «строительства» советы начнут концентрироваться на вопросах стратегической эффективности. Для этого помимо регламентов и процедур нужны правильно выстроенные коммуникации в компании, информация, процедуры стратегического анализа.

\section{2. Влияние структуры собственности на корпоративную эффективность}

В отличие от предыдущей работы, исследование Ирины Ивашковской и Анастасии Степановой фокусируется не на едином показателе качества корпоративного управления, а Выпуск \#4, 2007

() Электронный журнал Корпоративные Финансы, 2007 
на отдельном аспекте системы финансовой архитектуры компании, структуре собственности, которая тесно связана с процессом корпоративного управления. Так, например, исследование Иширо Ивасаки подтвердило прямое влияние структуры собственности на состав совета директоров.

Уникальность предложенного в докладе Ирины Ивашковской и Анастасии Степановой заключается в оригинальном подходе к изучению влияния одного из ключевых компонентов финансовой архитектуры компании на ее корпоративную эффективность. С тех пор, как в 2000 г. Майерс предложил понятие «финансовой архитектуры фирм», увязывающей структуру собственности, структуру капитала и систему внутреннего корпоративного контроля, исследования, подобные предложенному, получили четкое определение. В работе изучаются различные компоненты финансовой архитектуры, оказывающие то или иное воздействие на корпоративную эффективность.

В работе акцент сделан на нескольких новых постановках. Во-первых, изучено одновременное воздействие трех показателей структуры собственности (собственность менеджеров, институциональных инвесторов и концентрация собственности) на корпоративную эффективность российских компаний. Такая постановка основана на работах, которые вслед за выходом в свет исследования Морка, Шляйфера и Вишны [Morck, Shleifer и Vishny, 1988] были направлены на проверку характера воздействия структуры собственности на эффективность. Как мы уже говорили, одни авторы отвергают гипотезу существования подобной зависимости, другие утверждают, что собственность менеджеров положительно влияет на эффективность деятельности компании, увеличивая мотивацию к максимизации стоимости компании. Третий тип исследований выявляет немонотонное, Uобразное влияние. Для изучения второго типа агентских конфликтов - между разными видами собственников - авторы концентрируют внимание на вовлеченности акционеров в управление компанией. Поэтому вторая особенность подхода заключается во введении в исследовательскую модель показателя собственности в руках акционеров, вовлеченных в управление компанией вместо классического показателя концентрации собственности. Показатель собственности в руках акционеров, предложенный Ивашковской и Степановой, включает стратегических акционеров, которые, как правило, участвуют в управлении компанией, менеджеров-собственников, государство и институциональных акционеров, владеющих крупными пакетами акций. Авторы предполагают, что рост доли собственности вовлеченных акционеров увеличивает корпоративную эффективность благодаря их сильной мотивации максимизировать стоимость компании.

Авторы выделяют третий вид агентских конфликтов, возникающих внутри компании, это конфликт между институциональными инвесторами и другими акционерами. Главная цель институциональных инвесторов - минимизировать риск при поддержании небольшого заданного уровня доходности, то есть их цель отличается от цели частных акционеров, стремящихся максимизировать эффективность деятельности компании. Для анализа этого типа агентских конфликтов была предложена и протестирована следующая гипотеза: собственность институциональных инвесторов не оказывает значимого влияния на эффективность деятельности компании, так как эффект снижения эффективности деятельности, спровоцированный агентским конфликтом институциональных инвесторов с остальными собственниками, компенсируется положительным дисциплинирующим эффектом присутствия в компании институциональных инвесторов.

Базируясь на выдвинутых гипотезах, авторы построили так называемую модель классического типа с предпосылкой об экзогенном характере структуры собственности и структуры капитала. Модель включила в себя все возможные индикаторы собственности компании: собственность менеджеров, вовлеченных акционеров, государства и институциональных собственников. В исследовательской модели предусмотрен контроль структуры капитала компании, размера компании, темпа роста, и других показателей, характеризующих как отдельную фирму, так и отрасль в целом. Исследуя и моделируя корпоративную эффективность, авторы ставят вопрос о том, влияет ли страновой фактор на 
модель корпоративной эффективности. Они задаются целью проверить, зависит ли влияние структуры собственности на эффективность деятельности компании от страны, на данных которой проводится исследование. Для этого выборка была разбита на три части: развитые страны, развивающиеся страны и Россия; а затем были построены отдельные эмпирические модели по каждой группе и проведен сравнительный анализ результатов.

B 2002 г. Timoty Brailsford доказал на данных по австралийским компаниям, что структура капитала зависит от количества акций в руках менеджеров и мажоритариев. По словам Ивашковской и Степановой, если эта зависимость существует и на европейском рынке, то модель может привести к ложным выводам, так как до сих пор мы рассматривали структуру капитала и структуру собственности как независимые переменные. Поэтому третьей задачей работы стала проверка экзогенности структуры капитала и корректировка модели классического типа в случае выявления эндогенности структуры финансирования.

Авторами были представлены следующие выводы. Во-первых, вывод о том, что увеличение собственности акционеров, вовлеченных в управление компанией, ведет к росту рыночной эффективности деятельности компании, тогда как увеличение пакета акций у государства и аффилированных с ним компаний влияет на эффективность негативно. Авторы показали, что пакет акций в руках институциональных собственников не оказывает значимого влияния на рыночную эффективность компании, измеренную показателем Q Тобина. Во-вторых, интерес участников конференции вызвал выводы авторов о страновых различиях во влиянии структуры собственности на корпоративную эффективность. Применительно к развивающимся странам, таким как Турция, Греция, Польша и Венгрия, гипотеза о существовании зависимости между показателями структуры собственности и эффективностью деятельности компании не подтверждается. Это объясняется низким уровнем информационной прозрачности в развивающихся странах, что снижает качество данных, и, что наиболее важно, неразвитостью систем корпоративного управления в этих странах. Например, в большинстве турецких компаний, в том числе в крупных холдингах, все стратегические решения принимаются исключительно семьей, которой прямо и через аффилированных лиц принадлежит контрольный пакет акций компании.

Авторы показали также построенную ими модель зависимости между структурой капитала (сумма долга, деленная на бухгалтерскую стоимость собственного капитала) и структурой собственности. По их данным, выявленные благодаря модели показатели позволяют говорить об отсутствии значимой зависимости между структурой капитала и структурой собственности. Таким образом, классическая модель, базирующаяся на предпосылке экзогенности структуры капитала, имеет верную спецификацию, что опровергает выводы статьи Брэйлсфорда [Brailsford, 2002].

Подытоживая дискуссию, образовавшуюся на конференции по данным работам, попробуем ответить на несколько вопросов. В чем же разница между двумя последними исследованиями? Как так получается, что аспект структуры собственности (причем рассмотренный с точки зрения корпоративного управления) влияет на эффективность деятельности, а качество корпоративного управления на нее не влияет? Возможно, все дело в выборе показателей эффективности: рыночная эффективность и стратегическая имеют различные драйверы. Заметим, что выводы исследований не противоречат друг другу - они вполне могут существовать параллельно. Особенно хорошо это встраивается в вывод профессора Верникова о «декоративности» совета директоров. Если предположить наличие в большинстве исследуемых компаний «декоративных» советов директоров и соответственно напрямую управляющих собственников, то становится очевидным, что в условиях низкого уровня развитии всей системы корпоративного управления (что отражает рейтинг) вполне возможна высокая эффективность работы, которая обеспечивается высокопрофессиональными акционерами (с богатым опытом управления) и низким уровнем агентских издержек, поскольку других «сильных» стейкхолдеров в компаниях не наблюдается. Это нельзя назвать цивилизованной моделью управления: об интересах 
миноритариев еще мало где задумываются, но вполне можно допустить, что такая модель высокоэффективна.

Каждое из рассмотренных исследований генерировало новые гипотезы и новые выводы - подчас совершенно неожиданные и на первый взгляд сложно объяснимые. Однако каждый из этих выводов немного продвигает вперед науку и раскрывает до сих пор недоказанные взаимосвязи в еще мало изученном мире корпоративного управления российской экономики.

\section{Список литературы}

1. Авдашева С.Б. Бизнес-группы в российской промышленности // Вопросы экономики, 2004, № 5, c.121-134.

2. Капелюшников Р.И. Концентрация собственности и корпоративное управление. Препринт WP 1/2005/03. М.: ГУ-ВШЭ, 2005 г.

3. МФК Корпоративное управление в банковском секторе России. Исследование динамики улучшений. М.: Международная финансовая корпорация, 2007 г.

4. Радыгин А.Д., Энтов Р.М. Корпоративное управление и защита прав собственности: эмпирический анализ и актуальные направления реформ / Научные труды Института экономики переходного периода, 2001, № 36Р. М.: ИЭПП. 1932.

5. Berle A., Means G. The Modern Corporation and Private Property. New York: Macmillan,

6. Black, B. S. The Corporate Governance Behavior and Market Value of Russian Firms / Emerging Markets Review, 2001, № 2, p. 89-108

7. Brailsford T. J., Oliver B. R. and H. Pua S. L. On The Relation of Ownership Structure and Capital Structure / Accouting and Finance, 2002, № 42, p. 1-26.

8. Grossman S. and Hart O. One Share, One Vote and the Market for Corporate Control / Journal of Financial Economics, 1988, № 20, p. 175-202.

9. Hermalin B.E., Weisbach M.S. The determinants of board composition / RAND Journal of Economics, 1988, № 19, p. 589-606.

10. Hermalin B.E., Weisbach M.S. Endogenously chosen board of directors and their monitoring of the CEO / American Economic Review, 1998, № 88; p. 96-118.

11. Kesner I.F. Directors' Characteristics and Committee Membership: An Investigation of Type, Occupation, Tenure, and Gender / The Academy of Management Journal, 1988, № 31, p. 6684.

12. Kim W.S., Lee J.W. et Francis J.C. Investment Performance Of Common Stocks In Relation To Insider Ownership / Financial Review, 1988, № 23, 1, Février, p. 53-64.

13. Lloyd W.P., Jahera Jr. J.S. et Goldstein S.J. The Relation Between Returns, Ownership Structure, And Market Value / Journal Of Financial Research, 1986, № 9, 2, Été, p. 171-177.

14. Morck R., Shleifer A. and Vishny R. Management Ownership and Market Valuation: an Empirical Analysis / Journal of Financial Economics, 1988, № 20, p. 293-315.

15. Schellenger Michael H., David D. Wood and Ahmad Tashakori.Board of director composition, shareholder wealth, and dividend policy / Journal of Management, 1989, № 15p. $457-467$. 